Website: http://revistas.lamolina.edu.pe/index.php/acu/index

(C) Universidad Nacional Agraria La Molina, Lima - Perú

\title{
Identificación biomolecular y patogenicidad de Phytophthora, Pythium y Phytopythium aislados de raíz y suelo en cítricos (Citrus spp.)
}

\section{Biomolecular identification and pathogenicity of Phytophthora, Pythium and Phytopythium isolated of root and soil in citrus tress (Citrus spp.)}

\author{
Juan José Oviedo Quirós ${ }^{1 *} \&$ Luz Leonor Mattos Calderón ${ }^{2}$ \\ *Autor de correspondencia
}

\section{Resumen}

El objetivo de esta investigación fue identificar las especies de Peronosporales presentes utilizando métodos moleculares. Se recuperaron muestras de las raíces secundarias y suelo de ocho campos correspondientes a las cuatro principales regiones productoras a lo largo de la costa peruana (Piura, Lambayeque, Lima e Ica). Los Peronosporales se aislaron en medios de cultivo PAR, PARH y V8. La identificación molecular se realizó por amplificación de 730 - 820 pb de la región del espaciador transcrito interno (ITS) y de 563 pb de la región del citocromo oxidasa II (Cox II) del ADNr, usando cebadores ITS6/ITS4 y FM66/FM58 respectivamente. Los fragmentos amplificados se secuenciaron utilizando la metodología de Sanger y la reconstrucción filogenética se realizó con análisis bayesiano, utilizando dos millones de generaciones. Los resultados formaron grupos con las secuencias de especies similares depositadas en el GenBank, incluyendo: Phytophthora nicotianae, Phytopythium cucurbitacearum y Pp. vexans (aislados de raíz y de suelo), Ph. parsiana y Pythium splendens (aislados de raíz), Py. aphanidermatum, Py. ultimun, Py. deliense, Pp. amazonianum (aislados de suelo); además, se identificó una especie afín con Pythium guangxiense (aislado del suelo). Por otra parte, se realizaron las pruebas de patogenicidad cumpliendo con los postulados de Koch para cada uno de los aislamientos obtenidos, resultando patogénicos $P h$. nicotianae, $P h$. parsiana y $P$. vexans.

Palabras clave: Cítricos; Phytophthora; Pythium; Phytopythium; Identificación Biomolecular; ITS; Cox II; Análisis Bayesiano.

\begin{abstract}
The aim of this research was to identify the Peronosporales species using molecular methods. Samples from both secondary roots and soil were recovered from eight fields corresponding to the four main producing regions along the Peruvian coast (Piura, Lambayeque, Lima and Ica). Peronosporales were isolated on PAR, PARH and V8 agar media. Molecular identification was performed by amplification of $730-820 \mathrm{bp}$ of the Internal Transcriptional Spacer (ITS) and $563 \mathrm{pb}$ of Cytochrome Oxidase II (CoxII) regions of the rDNA, using ITS6/ITS4 and FM66/FM58 primers respectively. The amplified fragments were sequenced using Sanger methodology and phylogenetic reconstruction was done with Bayesian analysis, using two million generations. The results formed clusters with the similar species sequences deposited in the GenBank, including: Phytophthora nicotianae, Phytopythium cucurbitacearum y Pp. vexans (root and soil isolated), Ph. parsiana y Pythium splendens (root isolated), Py. aphanidermatum, Py. ultimun, Py. deliense, Pp. amazonianum (soil isolated). Also, a species related to Pythium guangxiense (soil isolate) was also identified. On the other hand, pathogenicity tests were carried out complying with Koch's postulates for each of the isolations obtained, resulting pathogenic $P h$. nicotianae, Ph. parsiana and $P$ p. vexans.
\end{abstract}

Keywords: Citrus, Phytophthora; Pythiu; Phytopythium; Biomolecular Identification; ITS; Cox II; Bayesian analysis.

\section{Introducción}

Taxonómicamente los cítricos se encuentran dentro del orden Genariales, la familia Rutacea, sub-familia Aurantioideas, tribu Citreae, sub-tribu Citrinea y género Citrus (Olivera, 1991).

Los cítricos verdaderos pertenecen a seis géneros (Citrus, Clymenia, Eremocitrus, Fortunella, Microcitrus y Poncirus), sin embargo, solo tres de estos géneros son de importancia comercial: Poncirus (naranjo trifoliado), Fortunella (Kumquat) y Citrus. Siendo las especies del género Citrus, desde el punto de vista agronómico, las más importantes (Agustí, 2003).

Los cítricos tienen su centro de origen en Asia oriental, específicamente la vertiente cálida o meridional del Himalaya hasta China meridional, Indochina, Tailandia,

\footnotetext{
${ }^{1}$ Servicio Fitosanitario del Estado - Ministerio de Agricultura y Ganadería, apartado postal 1521-120 - San José, Costa Rica. Email: jjoviedoq@ gmail.com

${ }^{2}$ Profesor principal, Departamento de Fitopatología, Facultad de Agronomía - Universidad Nacional Agraria La Molina, apartado postal 12-056 - La Molina, Lima, Perú. Email: leomattos@lamolina.edu.pe
} 
Malasia e Indonesia (Davies \& Albrigo, 1994; Anderson et al., 1996). Todos los frutos cítricos de importancia comercial aparentemente se han originado de especies nativas del sudeste asiático (Mont, 1998a). Actualmente, el cultivo de cítricos se desarrolla en casi todas las regiones tropicales y sub-tropicales del mundo, contempladas entre los paralelos $44^{\circ} \mathrm{N} \mathrm{y} 41^{\circ} \mathrm{S}$ (Agustí, 2003).

Los cítricos están considerados en Perú, como uno de los grupos de frutales de mayor importancia económica tanto por el área total plantada como por la rentabilidad alcanzada por hectárea (Franciosi, 1995).

La costa del Perú presenta un microclima ideal para la producción de diferentes cultivos como los cítricos (Citrus spp. L.) destinándose principalmente para la exportación. En el año 2013,la producción nacional de limón fue de 228.47 tonelada y para el caso de mandarina 313.80 toneladas (MINAG-OEEE, 2014).

Una de las enfermedades que afecta a los cítricos es la muerte descendente ocasionada por Peronosporales de los géneros Phytophthora sp., Pythium sp. y Phytopythium sp., los cuales causan pudrición o lesiones necróticas en las raicillas absorbentes de los árboles, obstruyendo o dificultando la absorción de agua y nutrientes por parte de la planta. El efecto del daño se refleja en la parte aérea donde se observa amarillamiento y decaimiento foliar, un retraso en el crecimiento y la muerte descendente del árbol, llegando a matarlo, lo cual afecta la productividad y comercialización de estas frutas (Mont, 1997).

En el Perú hay escasos reportes de pseudohongos radiculares, asociados a los cítricos. A la fecha las pudriciones radiculares han sido atribuidas a Phytophthora parasitica (Syn. Phytophthora nicotianae) Dastur, como agente causal (Javier, 1998; Chumacera et al., 2004; Javier, 2004a; Javier, 2004b y Rodríguez-Gálvez y Maldonado, 2004). Actualmente en diferentes países, se mencionan asociadas a diferentes cultivos especies de un nuevo género de la familia Pythiaceae: Phytopythium Abad, de Cock, Bala, Robideau, Lodhi \& Lévesque (Bala et al., 2010). Este género incluye individuos de características morfológicas intermedias entre Phytophthora y Pythium

Por lo expuesto, se planteó como objetivo general de la investigación determinar las especies de Peronosporales que afectan el sistema radicular en las plantaciones de cítricos a lo largo de la costa peruana.

\section{Materiales y métodos}

Aislamientos: Se recuperaron muestras de las raíces secundarias y suelo de ocho campos correspondientes a Piura, Lambayeque, Lima e Ica, principales regiones productoras de cítricos a lo largo de la costa peruana, de las cuales se obtuvieron aislamientos de pseudohongos en dos medios selectivos, PAR (el cual utiliza como base Corn Meal Agar (CMA) al cual se le adicionan tres antibióticos (Pimaricina, Ampicilina y Rifampicina), y PARH (el cual utiliza como base CMA más los tres antibióticos mencionados y la adición de Hymexazol). La siembra de las muestras (raíces y suelo) se realizó colocando cinco puntos de siembra en cada uno de los medios de cultivo, hasta obtener cultivos axénicos, las placas sembradas se incubaron a $25^{\circ} \mathrm{C}$, el cultivo puro se repicó en medio de cultivo Agar-V8 modificado (jugo V8 $50 \%+$ extracto de avena $50 \%$ ), para favorecer el desarrollo de micelio que fue utilizado en la extracción de.

Prueba de patogenicidad: se utilizaron plantas francas de aproximadamente dos meses y medio de edad, contenidas en bolsas plásticas con sustrato (arena, tierra de chacra y compost en relación 1:1:1), las cuales fueron tratadas, inmediatamente después de trasladadas e instaladas en el invernadero, con Tiabendazol (250 cc / 200 1. de agua). Dos meses posteriores a la desinfestación del sustrato, se realizó la inoculación con zoosporas a una concentración de 1 x $10^{4}$ zoosporas / $\mathrm{ml}$. de agua, aplicando $25 \mathrm{ml}$. por planta.

Al no mostrar síntomas, trascurrido dos meses desde la inoculación, se realizó una segunda inoculación utilizando micelio, propagado en trigo, a razón de 5 gr. de trigo inoculado por kilogramo de sustrato, usando entre 15 y 20 gr. de inóculo por planta.

Las plantas que presentaron síntomas secundarios fueron procesadas (extracción y siembra de raicillas en medio de cultivo CMA-PAR) antes de su muerte. La totalidad de las plantas fueron procesadas a los tres meses y medio de la primera inoculación (mes y medio después de la segunda inoculación); para ello, se procedió a lavar las raicillas y observar presencia de síntomas primarios para re-aislar el patógeno inoculado y así cumplir con los postulados de Koch.

\section{Características culturales y morfológicas de las especies} patogénicas: La prueba de comprobación morfológica, consistió en producir estructuras de propagación de los diferentes aislamientos, para posteriormente realizar montajes y observaciones microscópicas de las mismas, comparando con las descripciones de diversos autores, esta prueba se realizó tanto a los aislamientos obtenidos inicialmente, para determinar su identidad con los resultados biomoleculares; así como, los re-aislamientos obtenidos de las plantas inoculadas, para comprobar que se trató del mismo patógeno inoculado.

Análisis molecular: La extracción del ADN se realizó bajo la metodología de Cetyl Trimethyl Ammonium Bromide (CTAB) al $2 \%$ (Doyle \& Doyle, 1990). La prueba de PCR se llevó a cabo siguiendo las observaciones de Spies et al. (2011), utilizando los cebadores (primers) de la marca Sigma-Aldrich (Tabla 1). El ADN de las muestras se preparó mezclándolo con 7,86 $\mu 1$. de $\mathrm{H}_{2} \mathrm{O}$ HPLC estéril; 3,00 $\mu 1$. de Buffer para la Taq-polimerasa (Promega); 0,60 $\mu 1$. de dNTP's (Promega); 0,18 $\mu$ l. de primer $10,18 \mu \mathrm{l}$. de primer 2, 0,18 de Taq-polimerasa (Promega) y 3,00 $\mu 1$. de $\mathrm{ADNr}$, obteniendo un volumen total de $15 \mu \mathrm{l}$. por muestra y la reacción de PCR se efectuó en un termociclador BioRAD (modelo C1000 Touch) siguiendo las siguientes 
condiciones de termociclado ITS: $94^{\circ} \mathrm{C}$ pro 3 min., 35 ciclos de $\left(94^{\circ} \mathrm{C}\right.$ por $1 \mathrm{~min}$., $55^{\circ} \mathrm{C}$ por $1 \mathrm{~min}$. y $72^{\circ} \mathrm{C}$ por $1 \mathrm{~min}$.), $72^{\circ} \mathrm{C}$ por $10 \mathrm{~min}$ y $4^{\circ} \mathrm{C}$ al infinito y Cox II: $94^{\circ}$ $\mathrm{C}$ pro $5 \mathrm{~min} ., 30$ ciclos de $\left(94^{\circ} \mathrm{C}\right.$ por $60 \mathrm{seg} ., 52^{\circ} \mathrm{C}$ por 60 seg. $\mathrm{y} 72^{\circ} \mathrm{C}$ por $2 \mathrm{~min}$.), $72^{\circ} \mathrm{C}$ por $7 \mathrm{~min}$ y $4^{\circ} \mathrm{C}$ al infinito. mediante inferencia bayesiana con dos millones de generaciones y FigTree (versión 1.4.3).

El árbol filogenético se conformó con las secuencias obtenidas y con secuencias descargadas de la mega base GenBank, para conformar y respaldar los clados formados con las secuencias obtenidas. Además, se utilizó la secuencia de una especie totalmente diferente para que cumpla la función de raíz del árbol.

\begin{tabular}{llllc}
\hline Región & $\begin{array}{l}\text { Nombre } \\
\text { Primer. }\end{array}$ & \multicolumn{1}{c}{ Secuencia primer $\left(5^{\prime}-3^{\prime}\right)}$. & \multicolumn{1}{c}{ Referencia. } & $\begin{array}{c}\text { Longitud } \\
\text { fragmento }\end{array}$ \\
\hline \multirow{2}{*}{ ITS } & ITS4 & TCC TCC GCT TAT TGA TAT GC & White et al. (1990) & $730-882$ bp \\
& ITS6 & GAA GGT GAA GTC GTA ACA AGG & Cooke\& Duncan (1997) & \\
\multirow{2}{*}{ Cox II } & FM58 & CCA CAA ATT TCA CTA CAT TGA & Martin (2000) & \multirow{2}{*}{$563 \mathrm{bp}$} \\
& FM66 & TAG GAT TTC AAG ATC CTG C & Martin (2000) & \\
\hline
\end{tabular}

Los productos de PCR se limpiaron utilizando 3,5 $\mu 1$. del producto de PCR y añadiendo 1,4 $\mu$ l. de ExoSAP-IT (Affymetrix) bajo un programa sencillo de termociclado (15 minutos a $37^{\circ} \mathrm{C}$ y 15 minutos a $80^{\circ} \mathrm{C}$ ).

Estudio filogenético: el análisis bioinformático de las secuencias se realizó con la ayuda de los programas BioEdit Sequence Alignment Editor (versión 7.2.5), BLAST del National Center for Biotechnology Information (NCBI) (http://www.ncbi.nlm.nih.gov), MEGA (versión 7), MrBayes (versión 3.2.6). Se analizaron las secuencias

\section{Resultados y discusión}

Pruebas de patogenicidad: de todas las especies identificadas resultaron patogénicas Phytophthora nicotianae, Phytophthora parsiana y Phytopythium vexans (Figura 1), donde se puede observar que las plantas presentaban síntomas aéreos de amarillamiento, decaimiento y defoliación; mientras que los síntomas radiculares que presentaron fueron pudrición radicular y desprendimiento de la cubierta radicular quedando descubiertos los cilindros vasculares; siendo Ph. nicotianae el más agresivo.
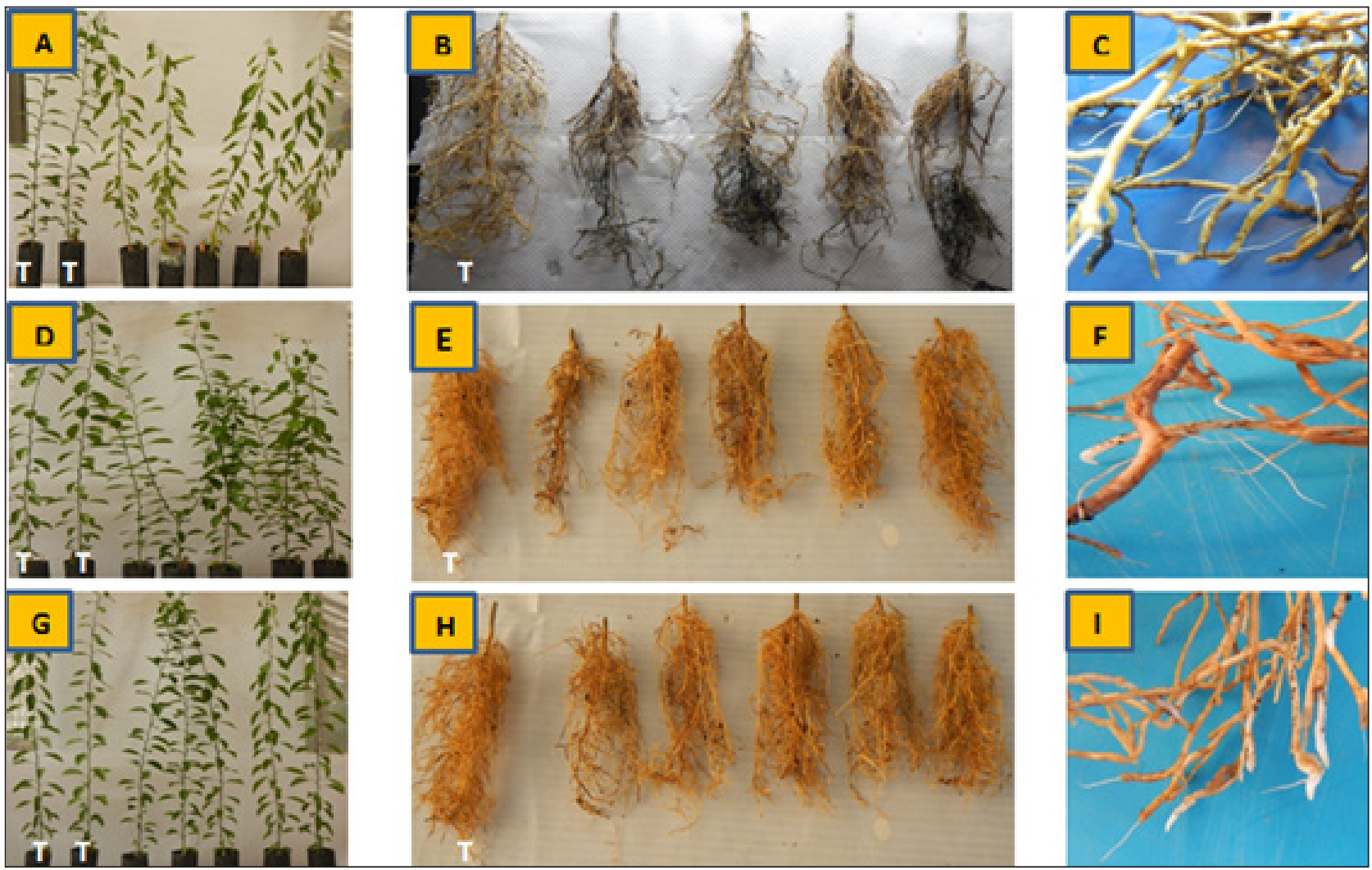

Figura 1. Síntomas presentados en la prueba de patogenicidad en el cultivo de cítricos para los aislamientos: Phytophthora nicotianae, A) parte aérea, B) raíces y C) pudrición radicular; Phytophthora parsiana, D) parte aérea, E) raíces y F) pudrición radicular; y Phytopythium vexans, G) parte aérea, H) raíces y I) pudrición radicular ( $\mathrm{T}=$ planta testigo) 
Características culturales y morfológicas de las especies patogénicas: en la Figura 2 se observa la forma de crecimiento, de las diferentes especies, en medio de cultivo CMA-PAR: Ph. nicotianae (A) toruloso y aéreo; Ph.parsiana (B) claveloide y superficial y Pp. vexans (C) asteroide y superficial.
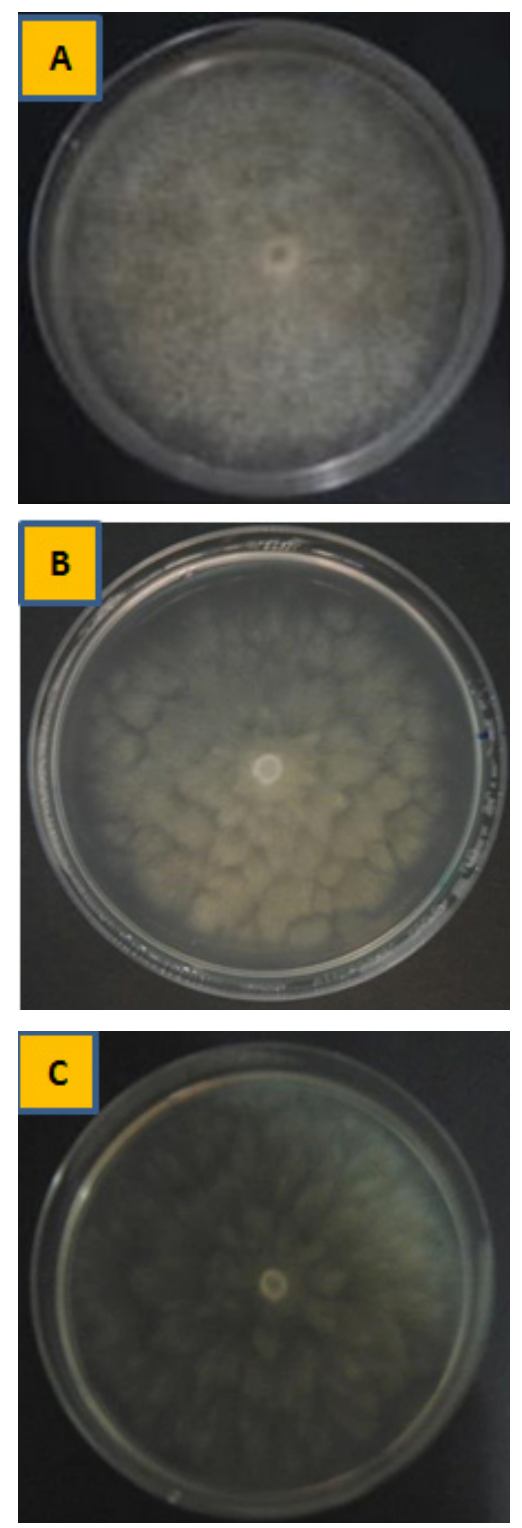

Figura 2. Aislamientos obtenidos en medio selectivo PAR, Phytophthora nicotianae (A), Phytophthora parsiana (B) y Phytopythium vexans (C)

La Figura 3, describe algunas características morfológicas de las especies patogénicas identificadas: $\mathrm{Ph}$. nicotianae (A), presenta zoosporangios (Zo) claramente papilados y persistentes, de forma ovoide a esféricos; clamidosporas $(\mathrm{Cl})$ globosas tanto terminales como intercalares; proliferación simpodial (Ps) y micelio (Mi) hialino no septado, similar a lo descrito por Waterhouse (1956), Erwin \& Ribeiro (1996) y Gallegly \& Hong (2008). Mientras que, Ph. parsiana (C), presenta zoosporangios (Zo) terminales, persistentes, no papilados y de formas elipsoides a obpiriforme; la clamidospora $(\mathrm{Cl})$ es esférica y de paredes delgadas; presenta proliferación interna (Pi) tipo anidado y su micelio (Mi) es hialino y aseptado, características que coinciden con las descritas por Mostowfizadeh-Ghalamfarsa et al. (2008). Por otra parte, en Pp. vexans(D), se observan zoosporangios (Zo) globosos con tubo de descarga (Van der Plaats-Niterrink, 1981).
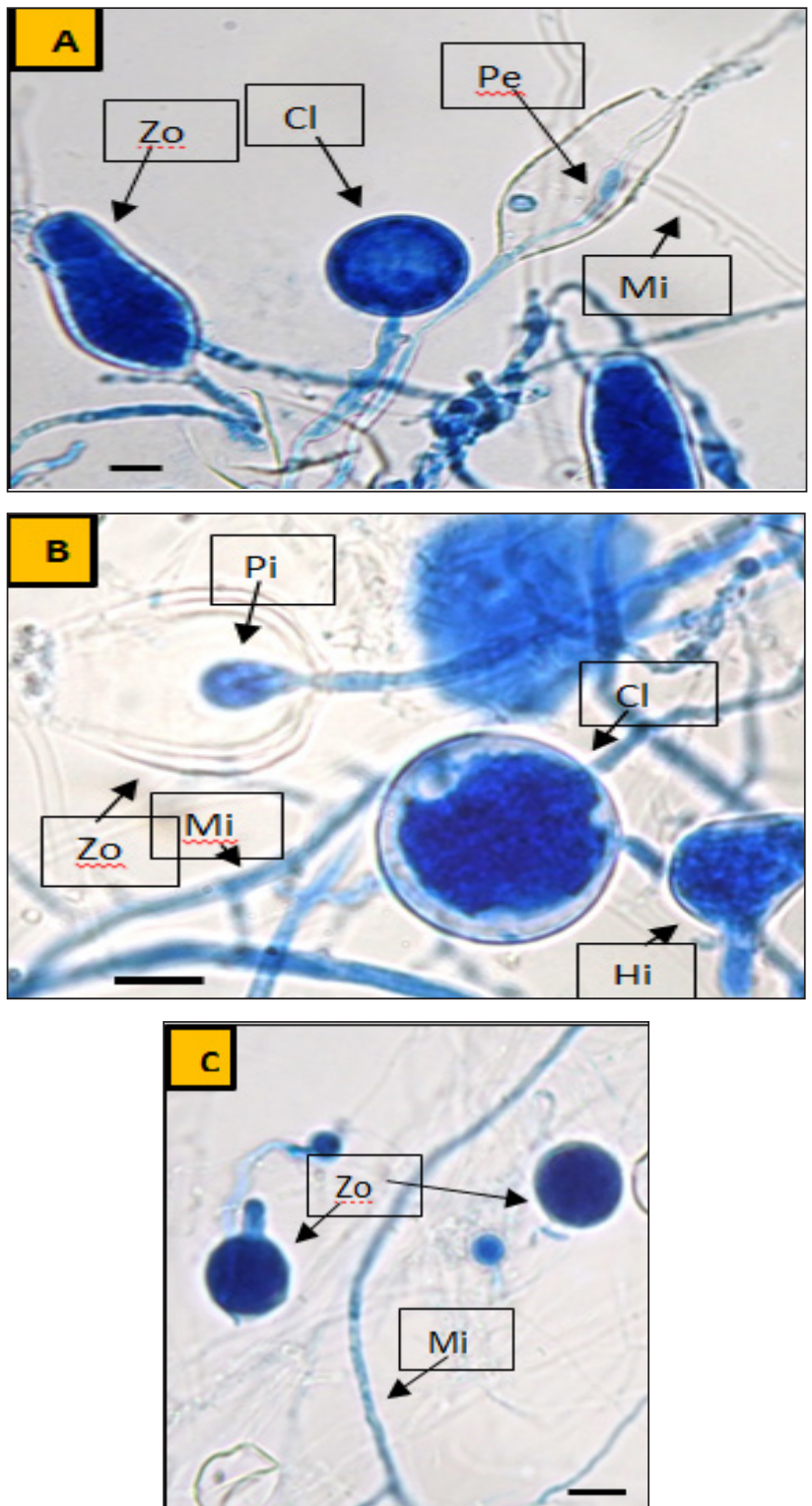

Figura 3. Estructuras morfológicas de las especies patogénicas en estudio, (A) Phytophthoranicotianae, (B) Phytophthora parsiana, (C) Phytopythium vexans. Zoosporangio (Zo), clamidospora $(\mathrm{Cl})$, micelio (Mi), hinchamiento hifal (Hi), proliferación extendida (Pe), proliferación simpodial (Ps), proliferación interna (Pi), oogonio (Og), oospora (Os), anteridio (An). Bar $=10 \mu$

Análisis molecular: en el Tabla 2 se detallan las especies de los géneros Phytophthora, Pythium y Phytopythium identificados a través del método de PCR para las regiones ITS y Cox II. 
Tabla 2. Especies de Phytophthora, Pythium y Phytopythium identificados, biomolecularmente (regiones ITS y Cox II), para cítricos, de las diferentes regiones muestreadas a lo largo de la costa peruana

\begin{tabular}{|c|c|c|c|c|}
\hline Patrón & Género / especie & Lugar & Distrito & Región \\
\hline \multirow{5}{*}{ Limón rugoso } & Phytophthora nicotianae & Guapalas & \multirow{5}{*}{ Chulucanas. } & \multirow{5}{*}{ Piura } \\
\hline & Pythium splendens & Chulucanas & & \\
\hline & Pythium deliense & Guapalas & & \\
\hline & Phytopythium vexans & Guapalas & & \\
\hline & Phytopythium cucurbitacearum & Chulucanas & & \\
\hline \multirow{4}{*}{ Limón rugoso } & Phytophthora nicotianae & San Isidro & \multirow{4}{*}{ Motupe } & \multirow{4}{*}{ Lambayeque } \\
\hline & Pythium sp. & El Carmen & & \\
\hline & Pythium aphanidermatum & San Isidro y El Carmen & & \\
\hline & Phytopythium vexans & San Isidro & & \\
\hline Limón rugoso & Phytophthora nicotianae & San Miguel, (Irrigacion Santa Rosa). & \multirow[t]{2}{*}{ San Miguel } & \multirow{4}{*}{$\begin{array}{l}\text { Lima (Hua- } \\
\quad \text { ral) }\end{array}$} \\
\hline Limón rugoso & Phytophthora parsiana & San Miguel, (Irrigacion Santa Rosa). & & \\
\hline Mandarina Cleopatra & Phytophthora nicotianae & La Villa, (Irrigacion Santa Rosa). & \multirow{2}{*}{ Huaral } & \\
\hline Mandarina Cleopatra & Pythium ultimum & La Villa, (Irrigacion Santa Rosa). & & \\
\hline Naranja Swingle & Phytopythium vexans & Pampa de los Castillos & Los Aquijes & \multirow{2}{*}{ Ica } \\
\hline Limón Criollo & Phytopythium amazonianum & San Juan Baustista. & San Juan Bautista & \\
\hline
\end{tabular}

Las secuencias de los aislamientos de estos tres géneros, para la obtención de árboles filogenéticos de la región ITS del ADN ribosomal, fueron analizadas mediante inferencia bayesiana con dos millones de generaciones, de igual manera, se obtuvieron secuencias confirmatorias de las especies en estudio, para la región Cox II del ADNr.

Estudios filogenéticos: en el árbol filogenético del género (Figura 4), se conformaron diez clados: el Clado $\mathrm{I}$, incluye a todos los aislamientos obtenidos de $P h$. nicotianae procedentes de los cultivos de cítricos de Piura, Lambayeque y de Lima (Huaral), los cuales se agrupan adecuadamente con las secuencias descargadas para esta especie; el Clado II, constituido por un aislamiento de $P y$. deliense obtenido del cultivo de cítricos procedente de Piura y de secuencias descargadas; el Clado III, comprende aislamientos de $P y$. aphanidermatum de cítricos procedentes de Lambayeque y de las secuencias descargadas para esta especie; el Clado IV, corresponde a un aislamiento de Pythium sp. de cítricos procedente de Lambayeque, que se agrupó con la secuencia descargada de Py. guangxiense, sugiriendo que estas dos especies están estrechamente emparentadas; el Clado V, está conformado por un aislamiento de $P$ y. splendens del cultivo de cítricos procedente de Piura, así como de las secuencias descargadas para esta especie; el Clado VI, lo conforma un aislamiento de Py. ultimum del cultivo de cítricos procedente de Lima (Huaral) y de secuencias descargadas para esta especie; el Clado VII, está constituido por aislamientos de $P p$. vexans del cultivo de cítricos procedente de Piura, Ica, y Lambayeque, además de secuencias descargadas para la especie; el Clado VIII quedó subdividido en dos, ambos subclados están conformados por aislamientos de $P p$. cucurbitacearum como de secuencias descargadas para la especie, los aislamientos en ambos subclados proceden de Piura de los cultivos de cítricos, se puede presumir que la división se puede dar por una diferencia genética entre los subclados; el Clado IX, lo conforman dos aislamientos del Pp. amazonianum obtenidos del cultivo de cítricos procedente de Ica y las dos únicas secuencias existentes en el GenBank, esta especie no presenta reporte ni descripción morfológica y por último el Clado X, está conformado por un único aislamiento obtenido de $P h$. parsiana de cítricos procedente de Lima (Huaral), el cual se agrupó con las secuencias descargadas para la especie.

Los resultados obtenidos por la identificación biomolecular, las pruebas de patogenicidad y el cumplimiento de los postulados de Koch, permiten confirmar la presencia de $P h$. nicotianae en los cultivos de cítricos, ratificando lo previamente descrito por varios autores. Numerosos estudios mediante identificación morfológica, han propuesto a $P h$. nicotianae como el agente causal de la pudrición radicular en cítricos (Javier, 1998; Chumacera et al., 2004; Javier, 2004a; Javier, 2004b, Rodríguez-Gálvez y Maldonado, 2004). Además Mont (1997) menciona en su descripción de la chupadera fungosa que uno de los agentes causales, pueden ser especies de Phytophthora que afectan la envoltura externa de las raicillas. Este mismo autor menciona que $P h$. parasítica (Syn. Ph. nicotianae) es uno de los agentes causales de la gomosis del cuello en cítricos, señalando que afecta las raicillas de los árboles. Anteriormente, García y Stevenson (1942) ya habían reportado la presencia de Ph. parasitica (Syn. Ph. nicotianae) en cítricos en la zona de Chanchamayo, departamento de La Libertad; de igual manera García (1947) indicó que este pseudohongo se encontraba afectando plantaciones de cítricos en los departamentos de Ancash, Arequipa (Camaná), Huánuco, Junín (Chanchamayo), La Libertad y Piura (Canchaque); así como, lo mencionan Bazán y Dongo (1965) y Bazán (1973; 1975). 


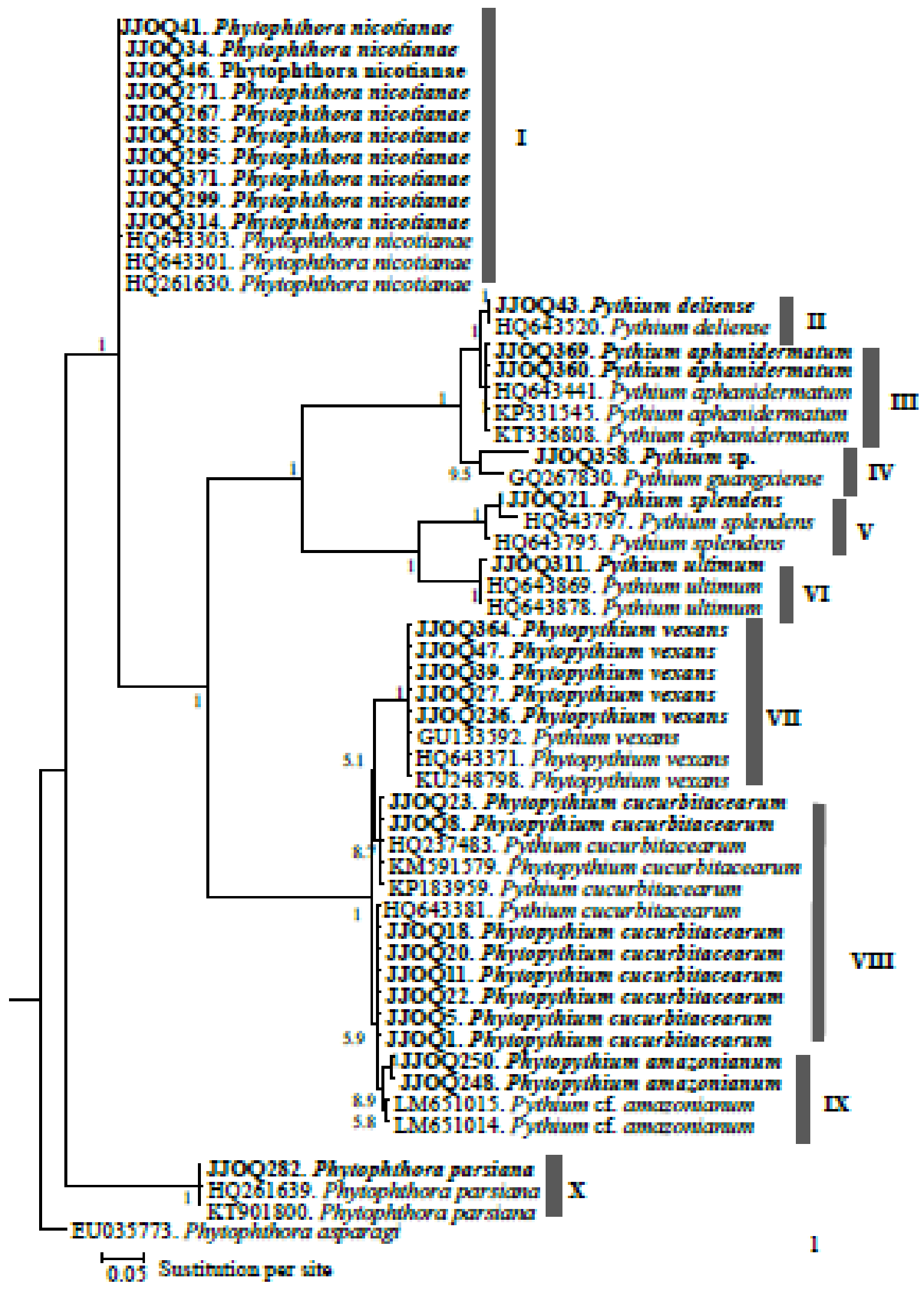

Figura 4. Árbol filogenético construido con secuencias correspondientes al ADNr del Espacio Transcrito Interno (ITS) de Phythophthora sp., Pythium sp. y Phytopythium sp., usando inferencia Bayesiana

(aislados en estudio, resaltados en negrita) 
En el caso de Ph. parsiana detectada en cítricos, solamente se obtuvo un aislamiento de la zona muestreada en Lima (Huaral), el cual corresponde a una muestra de raíz y no se encontraron reportes a nivel nacional de esta especie afectando cultivos de cítricos. Sin embargo, $P h$. parsiana fue reportada por primera vez como nueva especie del clado 9 de Phytophthora, afectando pistacho (Pistacia vera L.) en Irán y Estados Unidos, higo (Ficus carica L.) en Irán y almendra (Prunus dulcis Mill.) en Grecia (Mostowfizadeh-Ghalamfarsa et al., 2008); y afectando frutos de cítricos mediante una inoculación artificial (Hajebrahimi and Banihashemi, 2011).

Por otra parte, no existen reportes o estudios a nivel nacional para el género Phytopythium. Sin embargo, a nivel internacional Timmer et al. (2015) señala a Pp. vexans como el agente causal de "Damping-off” en cítricos, no obstante, antes del año 2010 donde se dio el surgimiento del género Phytopythium y la migración del clado K de Pythium a este nuevo género, en el Perú se reportaba a Pythium sp. como el agente causal de la pudrición radicular en palto (Bazán y Dongo, 1965; Bazán, 1973). Además, para Estados Unidos y Canadá se reporta $P p$. vexans en los cultivos de cítricos (Harvey, 1944b; Hendrix\& Campbell, 1968) coincidiendo con los resultados obtenidos en este estudio.

\section{Conclusiones}

Se logró identificar biomolecularmente mediante secuenciamiento de las regiones ITS y CoxII, así como ratificar con las características morfológicas, a los pseudohongos radiculares asociados al cultivo de cítricos (Citrus spp.): Ph. nicotianae, Ph. parsiana, Pythium sp., Py. aphanidermatum, Py. deliense, Py. splendens, Py. ultimum, Pp. amazonianum, Pp. cucurbitacearum y $P p$. vexans. Después de realizadas las pruebas de patogenicidad cumpliendo con los postulados de Koch, se determinó que los agentes causales de la pudrición radicular a lo largo de la costa peruana son: $P h$. nicotianae, $P h$. parsiana y $P p$. vexans en el cultivo de cítricos (Citrus spp.), considerando las dos últimas especies como un primer reporte para el Perú.

\section{Agradecimientos}

- Al Servicio Fitosanitario del Estrado (SFE) - Ministerio de Agricultura y Ganadería (MAG) de Costa Rica, por la beca otorgada para el estudio de la especialidad en Fitopatología.

- Al Departamento de Fitopatología de la Universidad Nacional Agraria L Molina (UNALM) en Perú, por brindarme y facilitarme los equipos y ambientes para el desarrollo de la investigación.

- Al Instituto de Biotecnología (IBT) de la Universidad Nacional Agraria la Molina (UNALM) en Perú, por la capacitación, prestamo de equipos e instalaciones del laboratorio para la extracción de ADN.

- A la Dra. Hilda Silva Rojas, directora del Laboratorio de Biotecnología y Patología de Semillas del
Colegio de Postgraduados (campus Montecillo) en México, por la capacitación, prestamo de equipos, reactivos e instalaciones del laboratorio para realizar procedimientos de PCR, secuenciación y análisis bioinformático.

\section{Literatura citada}

Agustí, M. 2003. Citricultura. Ed. Mundi-Prensa. Madrid, España. 422 p.

Anderson, C.; Banfi, G.; Beñatena, H.; Casafus, C.; Costa, N.; Danos, E.; Fabiani, A.; Garran, S.; Larocca, L.; Marco, G.; Messina, M.; Mika, R.; Mousques, J.; Plata, M.I.; Ragone, M.; Rivas, R.; Vaccaro, N. y Vazquez, D. 1996. Manual para productores de naranja y mandarina de la región del Río Uruguay (en línea). INTA (Instituto Nacional de Tecnología Agropecuaria). Eds. A. Fabiani, R. Mika, L. Larocca y C. Anderson. Argentina. (Serie A $\mathrm{N}^{\circ}$ 2, Diversificación Productiva). Disponible en: http:// inta.gob.ar/documentos/manual-para-productores-denaranja-y-mandarina-de-la-region-del-rio-uruguay/

Bala, K.; Robideau, G.P.; Levesque, C.A.; de Cock, A.W. A.M.; Abad, G.; Lodhi, A.M.; Shahsad, S.; Ghaffar, A. and Coffey, M.D. 2010. Phytopythium Abad, de Cock, Bala, Robideau, Lodhi\& Levesque, gen. nov. and Phytopythium sindhum Lodhi, Shahzad \& Levesque, sp. nov. Fungal Planet 49. Persoonia, 24: 136-137.

Bazán, C. 1973. Relación de enfermedades y microorganismos patógenos aislados de plantas cultivadas, forestales y ornamentales en el Perú. Ministerio de Agricultura. Lima, PE. 67 p.

Bazán, C. 1975. Enfermedades de cultivos frutícolas y hortícolas. Editorial Jurídica S. A. PE. 276 p.

Bazán, C. y Dongo, S. L. 1965. Lista de enfermedades y mricroorganismos aislados en plantas en el Perú. Ministerio de Agricultura. Lima, PE. 46 p.

Cooke, D.E. and Duncan, J.M. 1997. Phylogenetic analysis of Phytophthora species based on ITS1 and ITS2 sequences of the ribosomal RNA gene repeat. Mycological Research, 101: 667-677.

Chumacera, E.; Javier, J. y Murguía, C. 2004. Dinámica poblacional de Phytophthora parasitica Dastur. en plantaciones de limonero en el valle del Alto Piura. XVIII Congreso Peruano de Fitopatología. Huaraz, PE. $77 \mathrm{p}$.

Davies, F.S. \& Albrigo, L.G. 1994. Citrus. C.A.B. International. Great Britain. 244 p.

Doyle, J.J. \& Doyle, J.L. 1990. Isolation of Plant DNA from fresh tissue. Focus, 12:13-15.

Erwin, D. C. and Ribeiro, O. K. 1996. Phytophthora diseases worldwide. APS Press, American Phytopathological Society. USA. 562 p.

Franciosi, R. 1995. Manual de cultivo de frutales. Proyecto especial CHAVIMOCHIC. Trujillo, PE. 237 p.

Gallegly, M.E. and Hong, C. 2008. Phytophthora: Identifying species by morphology and DNA 
fingerprints. The American Phytopathological Society. USA. 157 p.

García, G. 1947. Fitopatología agrícola del Perú: una completa recopilación de las enfermedades fungosas, bacterianas y de virus de las plantas, constatadas en el país, a través de más de 20 años de investigación. Estación experimental agrícola de la Molina, dirección de agricultura y ganadería. Ministerio de Fomento. Lima, PE. 423 p.

García, G. y Stevenson, J.A. 1942. La flora fungosa peruana: lista preliminar de hongos que atacan a las plantas en el Perú. Estación experimental agrícola de la Molina, dirección de agricultura y ganadería. Ministerio de Fomento. Lima, PE. 112 p.

Hajebrahimi, S. and Banihashemi, Z. 2011. Host range of Phytophthora parsiana: a new high temperature pathogen of Woody plants. Phytopathol. Maditerr, 50: 159-165.

Harvey, J.V. 1944. Fungi associated with the decline of citrus and avocado in California. Pl. Dis. Reptr 28: 1028-1031.

Hendrix, F. F. Jr. \& Campbell, W.A. 1968. Pythiaceous fungi isolated from forest nursery soil and their pathogenicity to pine seedlings. Forest Sci. 14: 292-297.

Javier, J. 1998. Fungicidas y enmiendas orgánicas en el control de Phytophthora spp. en limonero Citrus aurantifolia (L.) Swingle injertado sobre Citru sjambhiri Lush, bajo riego tecnificado. Tesis para optar el grado de Magister Scientiae. Universidad Nacional Agraria La Molina. Lima, Perú. 115 p.

Javier, J. 2004a. Detección de Phytophthora parasitica en diferentes zonas citrícolas del norte del Perú. XVIII Congreso Peruano de Fitopatología. Huaraz, Perú. 77 p.

Javier, J. 2004b. Decaimiento de árboles de limón sutil injertados sobre limón rugoso basado en evaluaciones del aspecto externo del follaje en dos zonas citrícolas de Piura. XVIII Congreso Peruano de Fitopatología. Huaraz, Perú. 77 p.

Martin, F.N. 2000. Phylogenetic relationships among some Pythium species inferred from sequence analysis of the mitochondrially encoded cytochrome oxidase II gene. Mycologia, 92: 711-727.

MINAG-OEEE [Ministerio de Agricultura - Oficina de Estudios Económicos y Estadísticos]. 2014

Mont, R. 1997. Manual de enfermedades de los cítricos. Servicio Nacional de Sanidad Agraria. Lima, Perú. 72 p.

Mont, R. 1998 a. Los cítricos y sus enfermedades. Servicio Nacional de Sanidad Agraria. Lima, Perú. 44 p.

Mostowfizaadeh-Ghalamfarsa, R.; Cooke, D.E.L. and Banihashemi, Z. 2008. Phytophthora parsiana sp. nov., a new high-temperature tolerant species. Mycological Res. 112Ñ 783-794.

Olivera, C. 1991. El cultivo de los cítricos en el valle de
Huaral-Chancay. Fundación para el Desarrollo del Agro. 98 p.

Rodríguez-Gálvez, E. y Maldonado, E. 2004. Manejo de la pudrición radicular del limonero causado por el complejo Phytophthora parasitica - Tylenchulus semipenetrans. XVIII CongresoPeruano de Fitopatología. Huaraz, Perú. 77 p.

Spies, C.F.; Mazzola, M.; Botha, W.J.; Van Der Rijst, M.; Mostert, L. and McLeod, A. 2011. Oogonial biometry and phylogenetic analyses of the Pythium vexans species group from woody agricultural hosts in South Africa reveal distinct groups within this taxon. Fungal Biol. 115(2): 157-168.

Timmer, L.W.; Dewdney, M.M., Inserram, R.N. and Duncan, L.W. 2015. Diseases of Citrus (Citrus spp.) (enlinea). The American Phytopathological Society (APS). USA. Consultado 27 nov. 2016. Disponible en: http://www.apsnet.org/publications/commonnames/ Pages/Citrus.aspx

Van der Plaats-Niterink. 1981. Monograph of the genus Pythium. Central bureau voor Schmmelcultures. $242 \mathrm{p}$

Waterhouse, G. 1956. The Genus Phytophthora: diagnoses (or descriptions) and figures from the original papers. The Commonwealth Mycological Institute. 120 p.

White, T.J.; Burns T.; Lee S. and Taylor J. 1990. Amplification and direct sequencing of fungal ribosomal RNA genes for phylogenetics. In: Innis MA, Gelfand DH, Sninsky JJ, White TJ (eds), PCR Protocols: a guide to methods and applications. Academic Press, New York, 315-322 pp. 